\title{
LOKALITAS TARJAMAH HADITS BAHASA BETAWI: Respon Guru Mughni Terhadap Nilai Religius dalam Kitab Taudhih al Dalail fi Tarjamah Hadits al Syamail
}

\author{
Umayyatus Syarifah
}

Fakultas Sains dan Teknologi UIN Maulana Malik Irahim Malang Jalan Gajaaya No.50 Malang. Telp. 081357584993

email: umayyah.syarifah@gmail.com

\begin{abstract}
Taudhih al Dalail fi Tarjamah Hadits al Syamail is the manuscript hadith of Betawi's clerical work. The book is a translation of Muhammadiyah Syamail written by al Tirmidhi which teaches about the person and the attitude of the Prophet both in worship and social. It is translated by Guru Mughni of Kuningan, using the Arabic alphabet in Betawi Malay in 1926 AD. Guru Mughni categorized on the most popular one of the clergy late 19th and early 20th century in Batavia. With his compatriot friend, he was able to widen the intellectual influences that reach almost all parts of Batavia at the time. Social conditions of the religious community in Betawi during the Dutch colonial inspire Guru Mughni to build strong personal and character of Betawi community by making the Holy Prophet as a role model in life. Family background and education also makes his work has its own uniqueness over the works of Indonesian scholars at that time.
\end{abstract}

Taudhih al Dalail fi Tarjamah Hadits al Syamail merupakan naskah Hadits karya ulama Betawi. Kitab ini merupakan tarjamah atas Syamail Muhammadiyah karya imam Tirmidzi yang mengajarkan tentang pribadi dan sikap Rasulullah SAW baik dalam ibadah maupun sosial. Kitab tersebut dialihbahasakan oleh Guru Mughni Kuningan, dengan menggunakan huruf Arab Melayu dalam Bahasa Betawi pada tahun 1926 M. Guru Mughni dikategorikan salah satu ulama terpopuler akhir abad ke-19 dan awal abad ke-20 di Batavia. Bersama teman seperjuangannya, ia mampu melebarkan pengaruh intelektualitas yang menjangkau hampir seluruh wilayah Batavia saat itu. Kondisi sosial keagamaan 
masyarakat Betawi masa penjajahan Belanda, menginspirasi guru Mughni untuk membangun pribadi dan karakter yang kuat masyarakat Betawi dengan menjadikan Rasulullah SAW sebagai tauladan dalam kehidupan. Latarbelakang keluarga dan juga pendidikan menjadikan karyanya mempunyai keunikan tersendiri dibandingkan dengan karya-karya ulama Indonesia pada masa itu.

Key words: Hadits, religious value, Batavia

\section{Pendahuluan}

Perjalanan penulisan dan kodifikasi Hadits di dunia Islam mencapai 14 abad lamanya, dimana Hadits dan kajiannya mengalami perubahan bentuk pada setiap generasi. Hadits pada masa awal penulisan masih dalam bentuk yang orisinil seperti shahifah, ajza', rasail, muwaththo', mushannaf, musnad, sunan, jami', mustakhraj, mustadrak, zawaid, dan mu'jam. Pada masa berikutnya sampai sekarang, para ulama sebatas melakukan penulisan Hadits dalam bentuk ikhtishar, syarah, hasyiyah, tahqiq, tarjamah jam'u dan tadzkir.

Perkembangan literatur Hadits di Timur Tengah, secara periodik melahirkan tokoh-tokoh Hadits terkemuka yang menelorkan ratusan karya. Pada periode klasik diwakili oleh Imam Malik (w. 179 H), Syafi'i (w. 204 H), Bukhari (w. 256 H), Muslim (261 H), Nasai (w. 303 H), Ramahurmuzy (w.360 H), dan Khatib al Baghdadi (w. $463 \mathrm{H}$ ). Pada periode pertengahan diwakili oleh Ibnuu Shalah (w. 643 H), Ibnuu Hajar al Asqalani (w.862 H), dan al Suyuthi (w. 911 H). Pada periode modern diwakili oleh al Qasimy (w. 1332 H), Nashiruddin al Albani (w. 1998 M), Nur al Din al Itr, dan Ajjaj al Khatib (Rodliyana, 2004: 15-18).

Di Indonesia konsentrasi terhadap kajian Hadits muncul sejak Islam masuk wilayah Nusantara, namun perkembangannya belum begitu pesat. $\mathrm{Hal}$ itu disebabkan Islam masuk Indonesia mayoritas dibawa oleh para pedagang, bukan para ulama maupun syaikh (Syarifah, 2005: 2). Literatur-literatur Hadits berbahasa Arab pada awal masuknya Islam, peredarannya sangatlah minim. Hanya kiai, guru dan ulama tertentu yang mempunyai sejumlah literatur Hadits yang cukup. Hal ini seperti yang diungkapkan Martin van Bruinessen, bahwa perhatian ulama Indonesia pada pelajaran Hadits dan ulum al Hadits adalah hal baru, sehingga wajar bila masih sedikit sekali karya Hadits yang dihasilkan pada saat itu (Syarifah, 2005:2).

Meskipun Hadits dan kajiannya merupakan hal baru, bukan berarti Hadits tidak dipelajari pada masa Islam awal. Hal ini terbukti dengan ditemukannya karya Nur al Din al Raniri (w. 1658), Hidayah al Habib fi Raghib wa Targhib, 
yang berisi sejumlah Hadits yang berkenaan dengan penerapan syariat. Kitab tersebut diterjemahkan dalam Bahasa Melayu dan diinterpolasikan dengan al Quran. Di samping itu, juga ada karya Abdur Rauf al Sinkili, Syarah Hadits Arbain, dan al Mawaiz al Badi'ah yang ditulis atas permintaan kesultanan Aceh, Zakiyyah al Din yang berkuasa pada tahun 1678-1688 M (Azra, 1999: 186-196). Setelah masa al Raniri dan al Sinkili, Hadits mengalami stagnasi hingga awal abad ke-19, hal ini disebabkan masyarakat muslim ketika itu lebih fokus pada tasawuf.

Memasuki abad ke-19, Hadits merupakan materi baru di kalangan pesantren. Para ulama mulai menulis, mengumpulkan dan menterjemahkan kitab-kitab Hadits yang relatif cukup populer. Diantara yang dimaksud adalah Arbain al Nawawi, Sahih al Bukhari, Sahih Muslim dan Durrah al Nasihin. Beberapa pesantren, madrasah dan surau di nusantara menjadikan kitab-kitab Hadits terbitan Timur Tengah sebagai referensi pembelajaran dan pengajian yang dilaksanakan.

Salah satu ulama nusantara yang ikut memberikan sumbangsih dalam perkembangan literatur Hadits di Indonesia adalah Guru Mughni Betawi. Kondisi sosial masyarakat Betawi masa penjajahan menjadi motivasi tersendiri bagi guru Mughni untuk menterjemahkan kitab al Syamail al Muhammadiyah ke dalam Bahasa Betawi. Latar belakang keluarga dan juga pendidikan Guru Mughni, menjadikan karyanya memiliki keunikan tersendiri dari karya ulama Indonesia sebelumnya seperti al Sinkili, al Tirmasy, maupun ulama sesudahnya seperti Hasyim Asy'ari (1919 M).

Tulisan ini berangkat dari sebuah kesadaran tentang perlunya melihat peran dan kontribusi ulama Indonesia dalam merespon nilai religius dan pembentukan karakter bangsa yang bersifat lokal dengan menjadikan Hadits sebagai referensi utamanya. Karya tersebut ikut memberikan warna dalam sejarah perkembangan Hadits di Indonesia.

\section{Kehidupan Guru Mughni}

Abdul Mughni bin Sanusi bin Ayyub bin Qays, lahir di Kuningan Batavia pada tahun 1860 M. Ia adalah anak dari pasangan H. Sanusi Bin Ayyub dan $\mathrm{Hj}$. Daiyah binti Jeran. Ia dilahirkan dari keluarga yang sangat taat dalam menjalankan ajaran agama Islam. Intimidasi, diskriminasi etnis dan status sosial yang dilakukan Belanda, menjadikan masyarakat pribumi sulit mendapatkan pendidikan formal secara baik. Oleh karena itu, pendidikan awal Guru Mughni hanya didapatkan dari H. Jabir dan ayahnya dengan 
metode sorogan. Berkat keseriusannya dalam mendalami ilmu agama ditunjang dengan keluasan materi yang dimiliki keluarga, maka pada usia 17 tahun, ia dikirim ayahnya ke Mekkah untuk memperdalam ilmu agama (Fathullah, 2005: 23). Di antara guru-gurunya selama di Mekkah antara lain: Sa `id al Babsor, Abdul Karim al Daghostani, Muhammad Sa `id al Yamani, Umar bin Abi Bakar al Bajnid, Muhammad Ali al Maliki, Abdul Hamid al Qudsi, Muhammad Mahfuz al Termasy, Muhammad Mukhtar Mathorid al Bogori, Said Utsmani, Muhammad Hasbullah, Ahmad Zaini Dahlan, Muhammad Muslim Yasin, Muhammad Umar Syatho, Soleh Bafadhol, Ahmad Khatib al Minangkabawi dan Marzuki al Bantani (Fathullah, 2005: 23).

Setelah 14 tahun menuntut ilmu di Mekkah, Guru Mughni kembali ke tanah air guna mengajarkan ilmu di tempat asal, khususnya Kuningan. Pengajaran dilakukan di rumah dan di masjid. Menurut pengakuan putranya, Ali Syibromalisi, Guru Mughni membatasi jumlah santrinya kurang lebih 5 orang. Hal ini dimaksudkan agar santri memperhatikan dan memahami atas apa yang diajarkan. Guru Mughni mengajar ilmu fiqih menggunakan kitab Safinah al Najah dan Fath al Mu'in, ilmu tafsir menggunakan kitab Tafsir Jalalain, Hadits menggunakan kitab Shahih al Bukhari dan Shahih Muslim. Ilmu nahwu menggunakan kitab Alfiyah, sedangkan untuk ilmu akhlak ia menggunakan kitab Minhaj al Abidin (Fathullah, 2005: 26).

Hasil perjuangan Guru Mughni dalam pendidikan tidaklah sia-sia. Ia mampu menelorkan ulama Betawi terkemuka berikutnya, di antaranya adalah Guru Abdul Rachman Pondok Pinang, KH Mughni Lenteng Agung, Guru Naim Cipete, KH Hamim Cipete, KH Raisin Cipete, Guru Ilyas Karet, Guru Ismail atau Guru Mael Pendurenan, KH Abdurrachim dan KH Abdullah Suhaimi yang menjadi salah seorang guru dari Syekh Ahmad Nahrawi Abdussalam al Indunisi.

Semasa hidupnya, Guru Mughni sempat menikah delapan kali. Dua di antara istrinya adalah berkewarganegaraan Cina dan Belanda. Menurut salah seorang cucunya, pernikahan tersebut tidak dilakukan dalam satu masa secara bersamaan. Namun, empat istri adalah jumlah maksimal di setiap pernikahannya. Beberapa istrinya ikut juga membantu perjuangan dakwah Guru Mughni dalam menyebarkan nilai-nilai Islam (Fathullah, 2005: 25).

Guru Mughni sangat memperhatian pembentukan kepribadian dan masa depan anak-anaknya. Ia memiliki visi agar anak dan keturunannya mengikuti jejaknya untuk menjadi ulama. Oleh karena itu, ia mengirim putra-putrinya untuk menuntut ilmu di Mekkah walau usia mereka masih muda. Diantara 
putera-puteranya yang menjadi ulama, yaitu: Syahrowardi, Achmad Mawardi, Rochmatullah, Achmad Hajar Malisi, Ali Syibromalisi, Achmad Zarkasyi, dan Hasan Basri. Sedangkan dari cucunya, antara lain, yaitu Abdul Rozak Ma `mun, Nahrawi Abdus Salam, Abdul Azim AS, Abdul Mu` thi Mahfuz, Faruq Sanusi, dan Lutfi Fathullah.

Guru Mughni mempunyai kesadaran tinggi untuk meningkatkan kecerdasan, kesejahteraan, dan kehidupan sosial umat Islam, khususnya etnis Betawi yang tinggal di daerah Kuningan. Pada tahun 1926, ia mendirikan sebuah madrasah yang diberi nama Sa'adat al Darain (Fathullah, 2005: 29), yang sekarang berkembang hingga menjadi Perguruan Tinggi al Mughni dan Masjid besar Bait al Mughni yang terletak di Jl. Gatot Subroto Kuningan Jakarta. Ia juga dikenal sebagai seorang dermawan yang memberikan modal untuk para pedagang kecil guna mengembangkan usaha mereka tanpa meminta kembali pinjaman yang diberikan.

Menurut Saifuddin Zuhri, bersama empat teman seperjuangannya yaitu, Guru Marzuki, Guru Majid, Habib Usman, Guru Mansur, dan Guru Mahalli, Guru Mughni menyebarkan Islam, mengembangkan ilmu, membela rakyat sekaligus menanamkan semangat politik anti penjajahan dan penindasan. Abdullah Syafii menyatakan bahwa Guru Mughni adalah seorang pejuang yang mengorbankan masa hidup dan harta yang dimilikinya, guna mensosialisasikan syariat Islam dan menghidupkan sunnah Rasulullah SAW, hingga akhir hayatnya.

Guru Mughni wafat pada hari Kamis, 5 Jumadil Awwal 1354 H, dalam usia 70 tahun. Ia meninggalkan banyak tanah wakaf baik di Mekkah maupun di Jakarta, yang digunakan sebagai fasilitas umum. Di sela-sela perjuangannya selama setengah abad, guru Mughni menulis dua kitab, yaitu Naqlah min Ibarat al Ulama Nasihat Mauizah li Awlad al Zaman fi Adab Qiraat al Quran wa Ta'limih dan Taudhih al Dalail fi Tarjamah Hadits al Syamail yang akan dikupas pada tulisan ini.

\section{Masyarakat Betawi dan Masa Penjajahan Belanda}

Betawi adalah nama suku bangsa di wilayah DKI Jakarta dan sekitarnya, seperti di wilayah propinsi Jawa Barat dan Banten. Suku bangsa ini juga disebut orang Betawi atau 'Orang Jakarte'. Nama Betawi berasal dari kata 'Batavia', nama yang diberikan Belanda pada masa penjajahan (Supriatna, 2008: 614).

Suku Betawi terhitung pendatang baru di Jakarta. Kelompok ini lahir 
dari perkawinan antar etnis dan bangsa yang sudah lebih dulu hidup di Jakarta, seperti orang Sunda, Jawa, Arab, Bali, Sumbawa, Ambon dan Melayu. Menurut Antropolog Universitas Indonesia, Yasmine Zaki Shahab, bahwsa etnis Betawi baru terbentuk antara tahun 1815-1893 M. Pengakuan terhadap adanya orang Betawi sebagai sebuah kelompok etnis dan satuan sosial politik oleh Hindia Belanda baru muncul 1923 M, saat Moh. Husni Tamrin, salah satu tokoh Betawi mendirikan perkumpulan kaum Betawi (www. Wikipedia. com).

Penggolongan orang Betawi berdasarkan tempat tinggalnya terdiri dari: Pertama, Betawi Tengah, merupakan penduduk asli Betawi dan terletak di bagian tengah Kota Jakarta yang dulu merupakan kerisidenan Batavia, mendiami wilayah sekitar Gambir, Menteng, Senen, Kemayoran, Sawah Besar dan Taman sari. Tingkat perkawinan campur mereka cukup tinggi dibandingkan Betawi daerah lain. Berdasarkan tingkat ekonomi dan pendidikan, mereka termasuk yang paling tinggi karena mereka tidak hanya mengenyam pendidikan di dalam negeri bahkan di luar Negeri. Kedua, Betawi Pinggir, merupakan penduduk Betawi yang dari aspek Ekonomi termasuk ekonomi menengah, namun dalam bidang keagamaan mereka lebih taat. Mendiami wilayah sekitar Pasar Rebo, Pasar Minggu, Pulo Gadung, Jatinegara, Kebayoran, dan Mampang Prapatan. Ketiga, Betawi Udik, merupakan penduduk asli Betawi yang tinggal di daerah utara dan Barat Jakarta. Mereka sangat dipengaruhi kebudayaan Cina dan lainnya. Secara ekonomi pada umumnya Betawi Udik berasal dari ekonomi bawah dibandingkan yang lain, dimana sebagian besar mereka bertumpu pada pertanian. Keempat, Betawi Pesisir, mendiami wilayah sekitar Teluk Naga, Mauk, Japad, Tanjung Priuk, Marunda, Kelapa, dan kepulauan Seribu (Widyarini dkk, 2005: 1-2).

Sifat campur-aduk dalam dialek Betawi adalah cerminan dari kebudayaan Betawi secara umum, yang merupakan hasil perkawinan berbagai macam kebudayaan, baik yang berasal dari daerah-daerah lain di nusantara maupun kebudayaan asing. Meskipun demikian, Bahasa Melayu mempunyai peran yang sangat penting. Jakarta sebagai kota pelabuhan, kota dagang serta kota berbaurnya berbagai kelompok etnis, menjadikan Bahasa Melayu sebagai bahasa pergaulan. Bahasa Melayu di Jakarta diperkaya dengan kosa kata dari Bahasa Portugis, Cina, Arab, Belanda, Bali, Jawa, Sunda dan lain-lain, yang kemudian menjadi Bahasa Betawi (Supriyatna, 2008: 615).

Pada masa penjajahan, masyarakat Betawi meskipun telah memeluk Islam, masih melakukan hal hal yang berbau mistis, percaya akan pohon ataupun makam keramat yang memberikan kekuatan, dan keberkahan 
yang masih mewarnai sisi keagamaan mereka (Fathullah, 2005: 28). Pola hidup dalam berbusana dan sosialisasi sesama muslim masih jauh dari yang dianjurkan Islam. Ini menguatkan ungkapan Snouck Hurgronje, bahwa kaum muslim Indonesia lebih menghargai mistik daripada hukum Islam dan lebih menghargai pemikiran agama yang spekulatif daripada pelaksanaan kewajiban agama itu sendiri.

Islam masih bercampur dengan sisa peninggalan Hindu. Mistik mempunyai pengaruh di semua kalangan penduduk. Oleh karena itu, menurut Snouck, adat harus dipertahankan dan dibela dari propaganda ulama yang akan merubahnya (Iqbal, 2010: 251). Belanda berusaha melemahkan posisi Islam. Islam bagi mereka adalah sumber kekuatan yang akan menjadi pemersatu rakyat Indonesia untuk melawan penjajahan. Sikap Belanda yang pada awalnya akomodatif terhadap umat Islam menjadi intervensif dalam urusan keagamaan masyarakat pribumi, dan mengawasi gerak-gerik ulama demi kepentingan ketertiban dan keamanan. Hal ini tentu saja mendapatkan perlawanan di kalangan umat Islam Nusantara. Para ulama memainkan peranan penting dalam menggerakkan perlawanan tersebut. Sebut saja Cut Nyak Dien dan Teuku Umar di Aceh, Imam Bonjol di Minangkabau, Pangeran Antasari di Kalimantan dan pangeran Diponegoro di Jawa Tengah (Iqbal, 2010: 251).

Guru Mughni sebagai ulama di Batavia, berdakwah melalui pendidikan dan tulisan dalam membangun sisi patriotisme dan sisi religius masyarakat Betawi saat itu. Ia tidak sebatas berdakwah tentang nilai-nilai Islam, namun ia juga menanamkan anti penjajahan kepada masyarakat Betawi secara implisit di setiap dakwahnya. Melalui pendidikan, ceramah di setiap majelis pelosok Betawi, dan karya tulisnya, ia banyak memberikan perubahan dalam kehidupan masyarakat Betawi. Kebiasaan-kebiasaan buruk mulai ditinggalkan, sehingga terbentuk komunitas Betawi yang menjunjung tinggi nilai-nilai religius, menjadi pemeluk Islam yang fanatik. Nuansa Islam sangat dominan mewarnai kehidupan keseharian mereka. Hal itu terlihat pada sistem keyakinan yang terwujud pada rangkaian upacara daur hidup seperti tujuh bulan kandungan, aqiqah, sunatan, mauludan, qurban dan tahlilan. Semua upacara adat tesebut bernuansa islami (Pahlevi, 2009: 13).

Ajaran Guru Mughni bahwa hidup harus sesuai dengan ajaran Nabi Muhammad SAW adalah norma subyektif kelompok yang sangat dijunjung tinggi. Oleh karena itu, pendidikan yang diutamakan dalam masyarakat Betawi adalah pendidikan agama. Menurut Sobari, rakyat Betawi dilahirkan dalam 'suasana' Islam. Mereka belajar Islam sejak dini, dimulai dari lingkungan 
keluarga melalui proses sosialisasi yang kemudian dilanjutkan mengenal Islam dalam komunitas, yaitu belajar kepada guru ngaji. Sikap dan tingkah laku Nabi dipandang sebagai acuan bagi semua muslim seluruh dunia (Sobari, 2007: 126). Menurut Fauzi Bowo, keseharian kehidupan keluarga Betawi-pun pada dasarnya mencerminkan upaya merealisasikan ajaran Islam. Hal ini tercermin dari pertanyaan yang dilontarkan orang tua kepada anaknya ketika baru datang dari bepergian adalah shalat. Gambaran rutinitas masyarakat Betawi yang selalu melakukan sholat berjamaah di langgar, dilanjutkan dengan mengaji dan latihan pencak silat adalah kewajiban bagi remaja Betawi di masa itu (Fathullah, 2005: 30).

Guru Mughni memang tidak dikenal sebagai pahlawan kemerdekaan, namun ia adalah pejuang yang menanamkan nilai-nilai Islam. Melalui karyanya, ia mengajarkan kepada masyarakat Betawi cara berinteraksi kepada penciptanya, bersosialisasi kepada masyarakat dan membentuk pribadi dan sikap masyarakat Betawi berdasarkan sunnah Nabi SAW.

\section{Sekilas Mengenal Kitab Syamail dan Taudhih al Dalail}

Bentuk nyata perjuangan Guru Mughni dalam membangun nilai-nilai religius masyarakat Betawi, diantaranya adalah penulisan kitab Taudih al Dalail. Sesuai dengan judul, kitab ini merupakan terjemah atas kitab Syamail al Muhammadiyah waa Khashail al Musthafawiyyah karya Tirmidzi $(279 \mathrm{H})$ dengan menggunakan Bahasa Betawi. Kitab ini berisi Hadits tentang pribadi dan karakter Nabi Muhammad SAW yang dituangkan dalam bentuk riwayat yang dibagi dalam beberapa bab. Karya Tirmidzi sudah disyarah oleh beberapa ulama seperti Ibnuu Hajar al Makki al Haytami (w. 973 H), Muslih al Din M. Ibnuuu Shalah (w. 979 H), dan Ali Ibnuuu Sulthon M. al Qari (w. 1016 H).

Kitab Syamail juga diterjemahkan ke dalam Bahasa Turki pada tahun $1120 \mathrm{H}$ oleh al Maula Ahmad Ibnuu Khair al Din al Aidini, dan pada tahun $1158 \mathrm{H}$, diubah dalam bentuk puisi dengan menggunakan bahasa yang sama oleh Musthafa Ibnuuu Husein al Halabi (Fathullah, 2005: 121). Kitab dengan ukuran 16,5x21,5 cm ini dicetak di percetakan Sayyid Yahya bin Uthman bin Yahya Tanah Abang pada bulan Rajab tahun 1349 H/1926 M. Guru Mughni menterjemahkan kitab Syamail Muhammadiyah dengan judul kitab Taudhih al Dalail fi Tarjamat Hadits al Syamail.

Meskipun ia tidak menjelaskan alasan penulisan kitab secara eksplisit dalam mukaddimah, namun melalui isi kitab yang menjelaskan pribadi Rasulullah SAW baik secara fisik maupun karakter, penulis melihat ada 
semangat yang ingin disampaikan oleh Guru Mughni kepada masyarakat Betawi, bahwa Nabi Muhammad SAW adalah sumber inspirasi dan teladan bagi umatnya, maka sudah sepatutnya, umat Islam mempraktikkan sunnahsunnah Rasul dalam kehidupan sehari-hari.

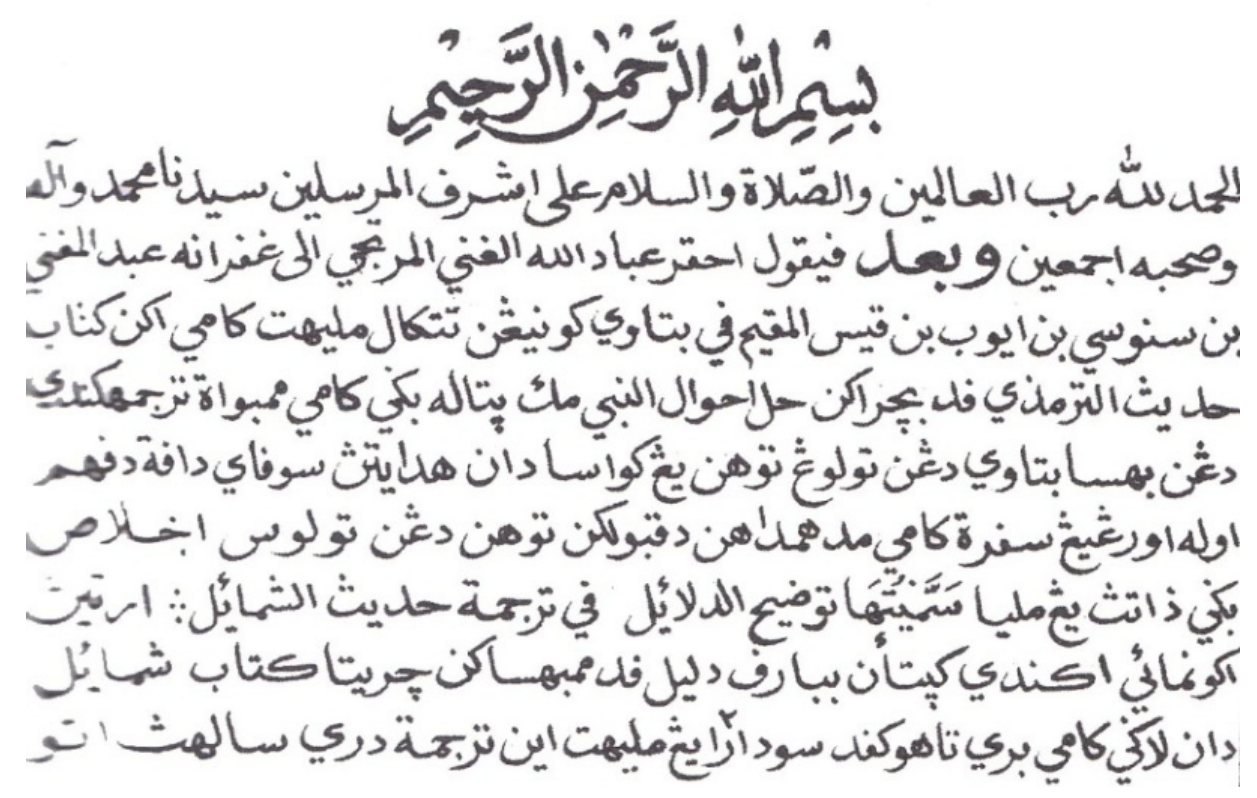

Gambar 1. Mukaddimah kitab Taudhih al Dalail Guru Mughni Betawi

Ia menulis kitabnya menjadi 57 lembar huruf tulis Arab Melayu dengan menggunakan Bahasa. Susunan bab diterjemahkan sesuai kitab asal. Hadits dalam setiap bab tidak dicantumkan secara keseluruhan. Hal ini dilakukan untuk menghindari pengulangan sanad dan matan Hadits yang notabene perawi dan kandungan Haditsnya sama. Sanad Haditsnya disebutkan hanya sampai tingkatan sahabat. Ini berbeda dengan kitab asal karya Tirmidzi yang mencantumkan seluruh perawi Hadits. Kitab Syamail karya Tirmidzi memuat 396 Hadits dengan sanad dan matan secara lengkap, sedangkan Guru Mughni dalam Dalail meringkasnya menjadi 305 Hadits. 


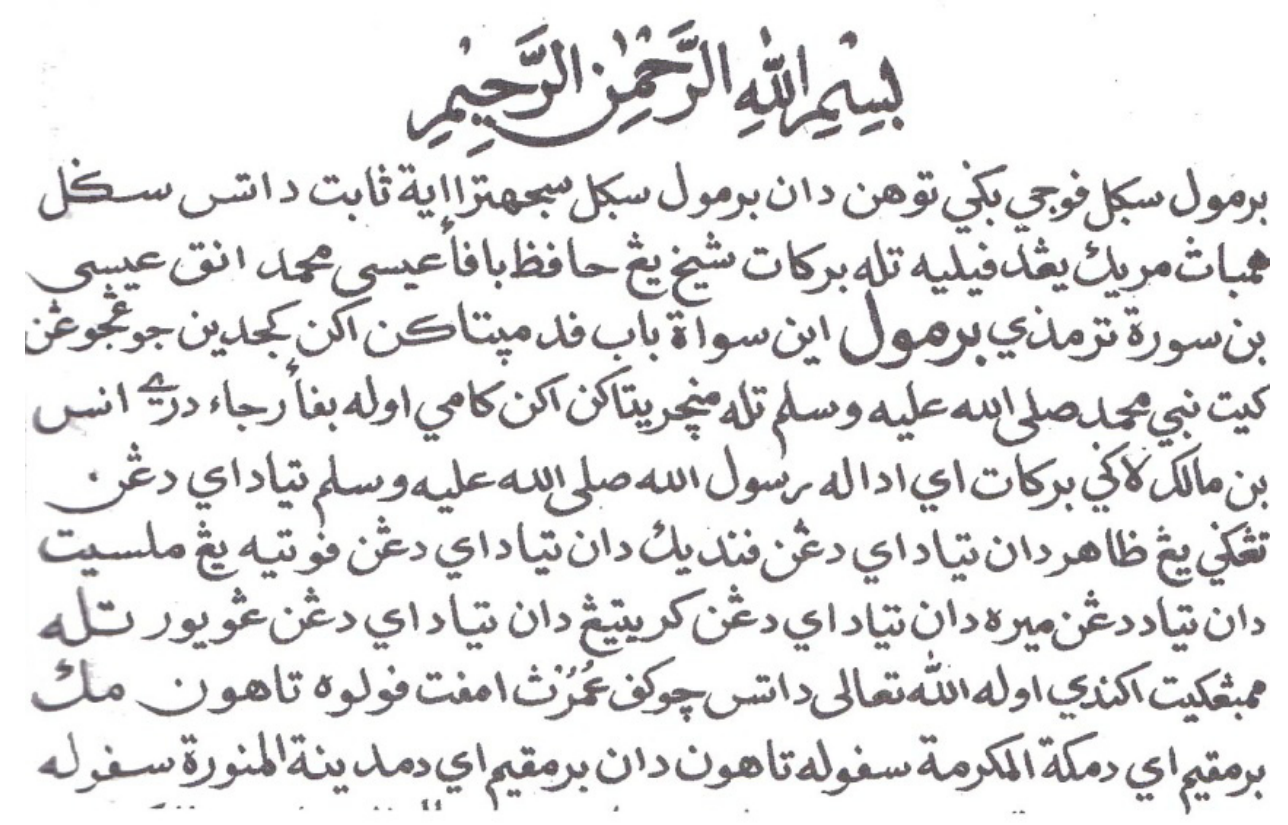

Gambar 2. Terjemah Hadits bab I (bentuk fisik Rasulullah SAW)

Pendidikan yang ditempuh selama 14 tahun di Mekkah sedikit banyak mempengaruhi Guru Mughni dalam menterjemahkan kitab tersebut. Pada beberapa Hadits, ia masih menggunakan bahasa asli (Arab) di beberapa tempat seperti: wal hal, menghafidz, idam, tsabit, litha'am dan lain-lain. Penerjemahan pun dilakukan secara literal dan tekstual. Format seperti ini, mungkin diharapkan agar setiap orang dengan mudah mengetahui arti dan kedudukan setiap kata (nahwu dan sharf).

Adapun penggunaan bahasa tutur dalam penerjemahan kitab ini lebih pada bentuk bahasa sopan yang biasa digunakan kepada mereka yang lebih tua seperti (nguyur: panjang, melesit: kemerah-merahan, belikat: daun telinga). Hal ini sesuai dengan sifat masyarakat Betawi yang dikenal sebagai masyarakat egaliter, tidak ada pembedaan penggunaan bahasa terkait strata sosial.

Kitab Taudih al Dalail karya Guru Mughni telah ditahqiq dan ditakhrij oleh Luthfi Fathullah cucunya sendiri. Menurut penulis, pentahqiq tetap mempertahankan teks asli kitab, menterjemahkannya ke dalam Bahasa Latin, menambahkan tanda baca untuk mempermudah bacaan, dan memberikan nomor pada setiap bab. Seluruh Hadits ditakhrij dan ditahqiq dengan merujuk pada Sembilan Kitab Hadits (Muwatho' Imam Malik, Sahih Bukhari, Sahih 
Muslim, Sunan Abu Daud, Sunan Ibnuuu Majah, Sunan al Tirmidzi, Sunan al Nasai, Sunan al Darimi, dan Musnad Ahmad bin Hanbal) dengan memberikan komentar di footnote.

\section{Nilai religiusitas kitab Taudhih al Dalail}

Religius adalah kata kerja yang berasal dari kata religion. Menurut Bouman, religion bertugas untuk mengatur kehidupan seseorang sehari-hari agar selalu berada dalam bimbingan Tuhan. Mangunwidjaya menjelaskan bahwa agama lebih menitikberatkan pada kelembagaan yang mengatur tata cara penyembuhan manusia kepada penciptanya dan mengarah pada aspek kuantitas. Sedangkan religiusitas lebih menekankan pada aspek kualitas manusia beragama. Keduanya merupakan kesatuan yang saling mendukung dan melengkapi, karena keduanya merupakan konsekuensi logis kehidupan manusia baik secara pribadi maupun sosial (Pudjiono, 2006: 15).

Religiusitas dimaksudkan sebagai pembuka jalan agar kehidupan orang beragama menjadi semakin intens, dan intensitas tidak dapat dipisahkan dari keberhasilan untuk membuka diri secara kontinyu terhadap pusat kehidupan. Karena ia adalah dimensi yang berada dalam lubuk hati dan sebagai getaran murni pribadi. Jadi religiusitas mencakup seluruh hubungan dan konsekuensi, antara manusia dengan penciptanya dan sesamanya (Pudjiono, 2006: 16).

Kriteria-kriteria religius dalam sebuah karya tulis, menurut Atmosuwito adalah berkenaan tentang hal hal berikut. Pertama, penyerahan diri dan tunduk kepada Allah SWT. Kedua, kehidupan yang penuh kemuliaan. Ketiga, perasaan batin yang ada hubungannya dengan Allah SWT. Keempat, perasaan batin yang ada hubungannya dengan doa. Kelima, perasaan batin yang ada hubungannya dengan takut. Keenam, pengakuan akan kebesaran Allah SWT (Pudjiono, 2006: 16).

Kitab Taudhih al Dalail bisa dikategorikan sebagai karya tulis yang lebih menitik beratkan pada nilai-nilai religius yang diajarkan Rasulullah SAW. melalui ucapan, perbuatan dan ketetapan. Kitab tersebut mengajarkan kepada manusia tentang cara berinteraksi kepada Penciptanya, bersosialisasi kepada sesama, dan mengajarkan hal yang sederhana seperti cara bersikap, cara berbusana, cara makan dan cara menghargai diri sendiri. Nilai-nilai religius yang tertulis dalam kitab Dalail, dapat dipahami dari Hadits-Hadits yang dipaparkan. Diantara nilai religius yang dipelajari dari beberapa Hadits yang diterjemahkan Guru Mughni dalam Bahasa Betawi adalah: Pertama, hubungan manusia dengan Allah SWT. Manusia sebagai makhluk ciptaan, pasti erat kaitannya 
dengan sang pencipta, wujud dari hubungan tersebut melalui ritual ibadah seperti sholat ataupun doa. Beribadah kepada Allah SWT mempunyai tata cara sendiri. Seperti Hadits Rasulullah SAW yang mengajarkan cara berwudlu kepada umat Islam sebelum melakukan ibadah sholat.

Ahmad bin Mani' telah menceritakan kepada kami, dari Ibnu Abbas, bahwa Rasulullah SAW keluar dari tempat wudhu, lalu sahabat bertanya: "apakah kami juga harus mengambil air wudhu?" Rasulullah SAW bersabda, "saya diperintah wudhu sebelum sholat (HR Abu Daud, Tirmidzi, Nasai dan Ahmad).

Dalam beribadah pun Rasululah SAW memberikan contoh pengabdian seorang hamba:

Qutaibah bin Said wa Basyr bin Muadz menceritakan kepada kami dari al Mughirah ra, ia berkata: Rasulullah SAW melaksanakan sholat sampai bengkak kakinya, lalu sahabat bertanya kepada Rasul, "mengapa Rasul sholat sampai seperti ini, padahal Allah SWT telah mengampuni dosa-dosamu yang telah lalu dan yang akan datang? Rasul bersabda: "Aku melaksanakan sholat ini untuk bersyukur kepada Allah (HR Bukhari, Muslim, dan Tirmidzi).

Keberadaan Muhammad SAW sebagai seorang nabi dengan predikat ma'shum tidak menjadikannya lalai dalam beribadah, beliau mengajarkan kepada umatnya kualitas terbaik dalam pengabdian sebagai seorang hamba Allah SWT. Manusia yang tidak memiliki jaminan surga seperti halnya Nabi SAW, sudah seharusnya melakukan ibadah seperti bahkan melebihi ibadah yang dilakukan Nabi SAW.

Nilai religius Hadits-hadits di atas termanifestasikan melalui rutinitas masyarakat Betawi dalam beribadah. Buya Hamka menyebutnya sebagai bentuk keislaman unik yang berbeda dengan masyarakat muslim daerah lain, dan Belanda kala itu mengakui hal tersebut. Sebuah masyarakat yang terlihat taat dalam beribadah, fenomena keagamaan yang terlihat begitu antusias dalam pelaksanaannya. Masjid, majlis ta'lim bahkan rumah menjadi sarana untuk melakukan ibadah seperti sholat, tahlil, shalawat dan doa bersama.

Pada dasarnya masyarakat Betawi selain memeluk Islam, juga masih mempercayai takhayul. Mereka meyakini bahwa hal hal yang berada di luar batas kemampuan manusia adalah dunia gaib yang meliputi,

1. Dewa-dewa jahat maupun baik.

2. Makhluk halus yang baik maupun yang jahat. 
3. Kekuatan sakti yang memberi manfaat dan membawa bencana. Mereka menempati area persimpangan jalan, kuburan leluhur, dan pohon-pohon besar.

Oleh karena itu, pada sebagian besar masyarakat Betawi masih menjalankan upacara tradisi berdasarkan kepercayaan masyarakat terhadap hal hal gaib, serta upacara yang berhubungan dengan siklus hidup yang meliputi akikah, sunatan, nikah, sedekah bumi dan lain-lain (Supriyatna, 2008: 619-632). Melalui pemahaman Hadits yang diajarkan Guru Mughni, maka tradisi-tradisi tersebut dilakukan dengan nuansa yang lebih islami yang awalnya mantra dukun diganti dengan ayat-ayat al Quran dan shalawat Nabi.

Kedua, hubungan manusia dengan lingkungan masyarakat. Setiap individu akan selalu berhubungan satu dengan lainnya dalam kelompok. Kelompok tersebut adalah masyarakat, dan individu sebagai anggotanya akan selalu mematuhi dan mentaati aturan yang berlaku di dalamnya sebagai bentuk pengikatan diri dan sarana pertahanan diri.

Sebuah riwayat menjelaskan:

Sufyan bin Waqi' telah menceritakan kepada kami, dari al Husein, ia bertanya kepada Ayahku (Ali) perihal Rasulullah SAW, saat duduk dengan sahabatnya maka ia berkata: "Rasulullah SAW itu berkelakuan ramah, berwajah bahagia, rendah hati, tidak berkata keji, tidak menggibah, tidak berteriak, tiada menjerit, tidak pelit dan tidak melalaikan diri dari barang yang tidak diinginkan, dan tidak memutuskan akan orang yang mengharap padanya. Menjauhkan dirinya dari tiga perkara; pertama, berbantah, kedua; berlebihlebihan, ketiga; barang yang mencelakakan dia (HR Tirmidzi).

Isa bin Yunus telah menceritakan kepada kami dari Aisyah ra, bahwa Nabi SAW adalah menerima hadiah dan membalas hadiah (pemberian) itu (HR Bukhari dan Abu Daud).

Nilai dari Hadits-Hadits tersebut tercermin pada sikap masyarakat Betawi dalam hidup bermasyarakat. Bagi masyarakat Betawi, seorang muslim adalah saudara muslim yang lain (Hadits), mereka harus saling membantu. Menurut salah seorang guru ngaji, seorang muslim harus memiliki solidaritas sosial, ia tidak diizinkan mengedepankan egonya, namun ia harus memprioritaskan kepentingan orang lain. Mereka juga dikenal sebagai masyarakat yang toleran dalam beragama dan menjunjung tinggi kebersamaan. Mereka tidak mengindahkan perbedaan agama. Masyarakat Betawi lebih cenderung pada 
sikap saling membantu dan akrab satu sama lain, mereka dikenal memiliki sikap saling tolong menolong jika ada umat lain memperingati acara keagamaan atau hari besar lainnya. Mereka menjaga keamanan dan kenyamanan bersama dan tenggang rasa jika umat lain sedang beribadah. Di samping itu, pada harihari besar seperti hari raya Idul Fitri, umat Islam memberikan kue kepada tetangga yang beragama lain, begitu juga sebaliknya.

Ketiga, hubungan manusia dengan dirinya. Sebagai makhluk pribadi, manusia mempunyai hak untuk menentukan sikap, pandangan hidup, dan perilaku sesuai kemampuannya, yang merupakan pembeda dengan manusia lain. Hak untuk menentukan keinginan sendiri itulah yang mencerminkan hubungan manusia dengan dirinya.

Dalam sebuah riwayat diceritakan:

Muhammad bin Mutsanna, dan Muhammad bin Basyar dari bapaknya Ishaq, telah menceritakan kepada kami, ia berkata: aku mendengar Abdurrahman bin Yazid bercerita dari Aswad bin Yazid, dari Aisyah bahwasanya ia berkata, "keluarga Rasulullah SAW tidak makan kecuali roti syair selama dua hari berturut-turut" (HR Bukhari, Tirmidzi dan Muslim).

Muhammad bin Sahal, telah menceritakan kepada kami dari Aisyah bahwa Rasulullah SAW bersabda, "sebaik-baik idam itu cuka (HR Muslim dan Tirmidzi).

Kesederhanaan yang ditampilkan Rasulullah SAW dan keluarganya dimulai dari asupan makanan sehari-hari, seperti: roti syair, cuka dan kurma, ketiganya merupakan makanan yang mudah didapatkan di Jazirah Arab, dan bukan kategori makanan mewah. Syair, khintah, dan bur, diterjemahkan dalam Bahasa Indonesia sebagai "gandum”. Roti syair merupakan gandum yang paling rendah mutunya, kadang kala dijadikan makanan ternak, namun dapat pula dihaluskan untuk makanan manusia. Ketiganya adalah makanan sederhana yang menjadi menu bersantap Rasulullah SAW dan keluarga sehari-hari.

Kesederhanaan dalam berbusana juga ditunjukkan Rasulullah SAW, melalui sebuah riwayat:

Abdun anak Humaid, dari Anas anak Malik telah menceritakan kepada kami, bahwa Nabi SAW berjalan bersama Usamah bin Zaid, dengan mengenakan baju Qithri dan berselendang surban, lalu Rasululullah SAW sholat dengan mereka (HR Ahmad).

Kain Qithri yang dimaksud adalah sejenis kain yang terbuat dari katun yang kasar, yang berasal dari Bahrain (Qatar). Kesederhanaan yang ditampilkan Rasulullah SAW sebagai teladan umat Islam, terekam dalam pribadi masyarakat 
Betawi. Hal ini dapat dilihat pada bentuk rumah Betawi yang sangat sederhana, busana yang dikenakan tidak banyak dipengaruhi budaya Barat, dan sikap yang ditunjukkan dalam kehidupan sehari-hari. Masyarakat Betawi lebih menggemari masakan-masakan sederhana yang mudah didapatkan dan murah seperti lontong sayur, nasi uduk, dan semur jengkol.

Ketegasan dalam bercakap diajarkan Rasulullah SAW melalui sebuah riwayat:

Hamid bin Mas'adah Bisri, telah menceritakan kepada kami dari Aisyah ra, ia berkata: "Rasulullah SAW tidak pernah terburu-buru seperti kamu ini, tetapi Rasulullah SAW selalu berkata tegas kepada para sahabat yang hendak menghafal perkataannya" (HR Tirmidzi dan Ahmad).

Rasulullah SAW juga memiliki rasa humor ketika berkomunikasi dengan para sahabat, sebuah riwayat menceritakan:

Mahmud bin Ghilan, telah menceritakan kepada kami dari Anas bin Malik bahwa Nabi SAW bersabda: "baginya wahai orang yang mempunyai dua telinga, Mahmud berkata bapak Usamah lagi menghadapi candanya (HR Tirmidzi dan Abu Daud).

Pribadi terbuka dan jujur serta humoris dimiliki oleh mayoritas masyarakat Betawi, dan akan selalu tampak dalam keseharian mereka. Kejujuran masyarakat Betawi terlihat menonjol pada pola komunikasi yang apa adanya. Hampir jarang ditemui kata untuk memperhalus maksud pembicaraan. Keterbukaan dan kejujuran masyarakat Betawi dalam keseharian inipun melahirkan sikap orang Betawi humoris. Hal ini mungkin untuk menghindari pertikaian karena sikap terbuka dan jujur mereka yang akan melukai hati orang lain.

Pribadi yang tegas dan sabar juga dimiliki oleh orang Betawi. Dikatakan meskipun hidup dalam kesusahan, orang Betawi tidak akan menjual keyakinan mereka. Kehidupan bagi orang Betawi adalah sebuah perjuangan dan kerja keras. Oleh karena itu, karakter pantang menyerah dan selalu mencari jalan keluar adalah ciri dari orang betawi asli. Dalam mengatasi masalah hidup menjadi kekuatan tersendiri masyarakat Betawi. Karakter ini juga melahirkan sifat berani menghadapi tantangan apa pun pada diri orang Betawi selama mereka meyakini apa yang mereka pilih itu benar (Ardian, Kompasiana: 2011).

Pribadi-pribadi yang dimiliki masyarakat Betawi dan kesesuaiannya dengan sunnah Nabi SAW bukan hal yang kebetulan semata. Guru Mughni 
mengajarkan nilai-nilai religius yang terdapat dalam kitab Taudhih al Dalail kepada masyarakat Betawi di penjuru Batavia melalui dakwah dan pendidikan, sebagai bentuk perjuangan pencapaian kualitas keimanan terbaik yang mencakup kualitas kesalehan kepada Allah SWT serta diiringi kualitas sosial dan individu dalam kehidupan.

Guru Mughni membentuk karakter masyarakat Betawi dengan menjadikan Rasulullah SAW sebagai tokoh utama yang layak untuk dijadikan contoh. Ia mensosialisasikan ajaran-ajaran yang terdapat dalam kitab dalail melalui majlis ta'lim dan juga madrasah yang ia bina. Islam Betawi yang pada awalnya masih bercampur mistik dalam kepercayaannya menjadi kuat dalam berakidah. Masjid, mushola dan rumah menjadi tempat untuk memperbaiki kualitas keimanan mereka. Melakukan ritual ibadah yang wajib hingga sunnah. Kehidupan sederhana yang diajarkan Nabi SAW menjadi ciri dari keseharian masyarakat Betawi. Ketegasan, keterbukaan dan kejujuran yang diajarkan Nabi SAW adalah nilai-nilai yang ditanamkan sejak dini. Sebagaimana yang dikatakan Sobari, Islam Betawi adalah Islam sepanjang hidup, dipahami dan dipraktikkan.

\section{Simpulan}

Taudhih al Dalail fi Tarjamah Hadits al Syamail merupakan naskah Hadits karya Guru Mughni. Kitab ini merupakan tarjamah atas Syamail Muhammadiyah karya Tirmidzi yang mengajarkan tentang pribadi dan sikap Rasulullah SAW baik dalam ibadah maupun sosial. Kitab tersebut dialihbahasakan oleh Guru Mughni Kuningan, dengan menggunakan huruf Arab Melayu dalam Bahasa Betawi pada tahun 1926 M. Sasaran utamanya adalah umat Islam Betawi yang berdomisili di Batavia.

Diantara keunikan karya ini dibandingkan karya Hadits ulama-ulama nusantara lainnya adalah penerjemahan dan pemilihan Hadits yang disesuaikan dengan tradisi-tradisi lokal. Guru Mughni menyoroti kebiasaan dan adat istiadat yang berkembang, baik yang berkenaan dengan akidah, etika dan budaya yang ada di masyarakat Betawi. Ketika merespon tradisi-tradisi di sekitar Betawi, guru Mughni merubah ritual yang benuansa mistis menjadi lebih islami. Membentuk pribadi masyarakat Betawi yang sederhana, tegas, terbuka dan jujur, dengan menjadikan pribadi Rasulullah SAW. sebagai teladan hidup. Guru Mughni menjadikan Islam layak untuk dianut, dipelajari dan dikaji, kemudian dipraktikkan. 


\section{Daftar Pustaka}

Ardian, Dery. 15 Agustus 2011. Kelakuan Orang Betawi. Kompasiana. Diakses pada 4 April 2012.

Azra, Azyumardi. 1999. Jaringan Ulama Timur Tengah dan Kepulauan Nusantara abad XVII dan XVIII. Bandung: Mizan.

Bruinessen, Martin Van. 2005. Kitab Kuning, Pesantren dan Tarekat. Bandung: Mizan.

Fathullah, Lutfi. 2005. Pribadi Rasulullah Telaah Kitab Taudih Dalail fi Tarjamat Hadits al Syamail. Jakarta: al Mughni Press.

Iqbal, Muhammad. 2010. Pemikiran Politik Islam Dari Masa Klasik Hingga Kontemporer. Jakarta: Kencana PMG.

Pahlevi, Abdurrazak. 2009. Analisis Perbandingan Pandangan Daur Hidup Pada Masyarakat Jepang dan Betawi. Skripsi. Universitas Sumatera Utara.

Pudjiono, M. 2006. Analisis Nilai-nilai Religius dalam Cerpen Karya Miyazawa Kenji. Skripsi. Universitas Sumatera utara.

Rodliyana, Dede. 2004. Perkembangan Pemikiran Ulum al Hadits dari Klasik hingga Modern. Bandung: Pustaka Setia.

Sobari, Muhammad. 2007. Kesalehan Sosial. Jogjakarta: Lkis

Supriyatna, Endang. 2008. Kepercayaan Tradisional dan Ketakwaan Terhadap Tuhan Yang Maha Esa dalam Sistem Sosial Budaya Masyarakat Betawi di DKI Jakarta, (Jurnal Penelitian, Vol. 40, no.1, 607-640. Balai Pelestarian Sejarah dan Nilai Tradisional Bandung.

Umaiyatus Syarifah. 2006. Pergeseran Pemikiran Ulama Hadits Indonesia abad 19-20. Tesis. UIN Syarif Hidayatulloh.

Widyarini, Nilam. Dkk. 2005 Menggali Potensi Kewirausahaan Masyarakat Betawi di Sawangan, Proceeding Seminar Nasional PESAT. Auditorium Univ. Gunadarma, ISSN:18582559. Halaman 208-219. 